\title{
НЕКОТОРЫЕ АСПЕКТЫ ПСИХОЛОГИЧЕСКОЙ ПОМОЩИ ЛИЦАМ, ЗАВИСИМЫМ ОТ ПСИХОАКТИВНЫХ ВЕЩЕСТВ (ПАВ)
}

Аванесян Г.Г. (Московский авиационный институт - национальный исследовательский университет, Москва, Россия)

ganaa2003@mail.ru

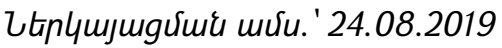

qпuһunuर्uाu uर्जu. '25.08.2019

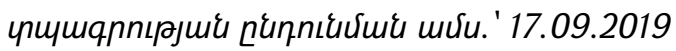

В данной статье рассматривается проблема зависимости от психоактивных веществ, рост наркомании в мире, способы оказания медицинской и психологической помощи. Описываются формы физической и психологической зависимости от психоактивных веществ, международная программа реабилитации наркозависимых по программе 12 шагов, которая успешно осуществляется в последние годы и в России тоже, что позволяет наркозависимым людям находиться в продолжительной ремиссии.

Ключевые слова: аддикция, зависимое поведение, наркомания, реабилитация.

В настоящее время в мире насчитывается большое количество различных зависимостей, которые негативно влияют на жизнь людей, определяют направленность их мотивов и действий. Среди них пищевая, игровая, компьютерная, сетевая и иные виды зависимостей. В психологии данное явление обозначается как аддикция.

Аддикция - это хроническое рецидивирующее заболевание, которое характеризуется, компульсивным поиском вещества и его употреблением; потерей контроля над его употреблением; возникновением негативного эмоционального состояния, когда доступ к веществу или его употребление становится невозможным» [4]. Среди всех фрорм аддикции наиболее сильное беспокойство у общества и государства вызывает проблема наркомании и алкоголизма, кратко обозначаемое как зависимость от ПАВ.

ПАВ - это такие вещества, злоупотребление которыми является опасным как для здоровья самого человека, так и для его близкого окружения. Так, многие наркотические вещества уже при однократном употреблении способны изменять самосознание человека и формировать зависимость от него. В медицине подобную физическую и психологическую зависимость называют наркоманией. Специальный раздел медицины, изучающий наркоманию - наркология, выявил такие многочисленные отклонения, как: ранняя смертность, соматические и невралгические болезни, психическая деградация личности, социальная опасность в передаче инфекционных болезней среди молодежи, криминогенное поведение, изменение морально-нравственной стороны личности. 
Известно, что количество наркозависимых людей в мире ежегодно растет. Так в докладе ООН по данным за 2017 год сообщается уже о 271 млн. человек по всему миру употребляющих каннабис, кокаин, опиум и синтетические наркотики [5].

Во всемирном докладе о наркотиках за 2018 год говорится, что за последние 20 лет количество смертей от употребления ПАВ увеличилось до 60\% . Есть наркоманы даже старше 50-ти лет, которые умирают от опиоидов, и по-прежнему большинство из них это мужчины. Опиоидный кризис, растущий уровень употребления рецептурных препаратов, рекордные показатели производства кокаина и героина приводят к тому, что все больше людей становятся наркоманами, несмотря на противодействия правоохранительных органов, растущее количество медицинских учреждений, общественных организаций и прочих структур помощи зависимым людям [6].

Известно, что при наркомании проявляется так называемая групповая физическая зависимость, когда компания употребляет одно и то же наркотическое вещество. Сама же физическая зависимость развивается на фоне постоянного употребления ПАВ, отмена которых вызывает абстинентный синдром. Это самое главное проявление фризической зависимости, развивающееся спустя несколько часов после того, как в организм не поступает очередная доза наркотика, что вызывает у наркомана вместо эйфории состояние депрессии, или же тревоги, и как следствие - компульсивное влечение к наркотику или любому иному токсическому веществу. Как отмечают различные специалисты - наркологи, психологи, психиатры, больной наркоманией неспособен признать у себя наличие зависимости от ПАВ, ему кажется, что употребление зависит полностью от его собственной воли, и он в любой момент сможет отказаться от наркотика.

По сравнению с российской практикой оказания помощи наркоманам, В международной практике нейролептики, антидепрессанты, транквилизаторы не используются как средства патогенентически ориентированные на купирование абстинентного синдрома или зависимого поведения [1].

В последние годы широкое распространение получила полинаркомания - это совмещение или сочетание в употреблении различных наркотических веществ, включая лекарства и алкогольные напитки. Такую одновременную зависимость от многих ПАВ принято называть осложненной наркоманией, что ведет к быстрому росту самодельных препаратов, влияющих на аппетит, зрение, вызывающих такие серьезные психологические проблемы, как: повышение раздражительности, конфликтности, требования денег от близких для приобретения наркотика.

Среди молодежи растет толерантность к определенным курительным смесям, так называемым легким наркотикам, к увеличению дозы в несколько раз, что ведет к появлению сильных болевых ощущений и спазмов в области живота, сердца, к расширению зрачков и учащению пульса, слезотечению и слюнотечению, одним словом - к общему ухудшению состояния здоровья вплоть до смерти. 
Многолетние исследования, проведенные мною и коллегами, работающими с наркозависимыми свидетельствуют о том, что для большинства зависимых от ПАВ (78\%) наркотическое вещество становится тем допингом, которым хочется вернуть работоспособность, настроение, аппетит, улучшить общее самочувствие. Когда-то полученный эфрфект заставляет наркомана продолжать употреблять ПАВ. По результатам наблюдения в стационаре продолжительное употребление ПАВ постепенно приводит к соматическим нарушениям, портятся кожные покровы, волосы, ломаются ногти, зубы, появляются запоры, у мужчин наступает импотенция, у женщин - аменорея, а также вирусные гепатиты, тромбофрлебиты изза постоянных уколов в конечности. Так, тяжелое истощение, астения и апатия делают наркозависимых нетрудоспособными, и они все время проводит дома.

При каннабиноидной наркомании состояние легкого опьянения развивается уже через несколько минут, наркоман испытывает разные эмоциональные состояния от веселья до страха, а в поведении проявляется агрессивность, потребность двигаться, повышенная говорливость, легкость в теле, своеобразное сужение сознания - впечатление, что видишь себя со стороны. Опьянение может длиться до нескольких часов, после появляется голод. При делирии возникают галлюцинации страха, от которых наркоман спасается бегством, растерянно оглядывается вокруг, не узнает окружающих; на контакт идет с большим трудом. Иначе говоря, состояние острого интоксикационного психоза может длиться от нескольких часов до нескольких дней. Часто при наркомании состояние сходно с параноидной шизофренией, иными словами - бред преследования сочетается с апатией, безволием, бездеятельностью, со слуховыми галлюцинациями. Наркотик по факту провоцирует развитие шизофрении, особенно при долгом употреблении. Зависимые от ПАВ также склонны принимать стимуляторы, антидепрессанты, обезболивающие препараты. Происходит полная социальная деградация, которая приводит к паразитическому образу жизни, воровству, преступности, при этом организм наркомана истощается, у него появляется апатия, бездеятельность, нарушение высших психических функций.

Эффрективным психологическим методом помощи зависимым от ПАВ является когнитивно-поведенческая терапия, которая помогает осознать причины употребления ПАВ. Также наркоман определяет ситуации, которых ему желательно избегать в будущем, у него стимулируется активность, меняются убеждения, вырабатываются определенные умения трезвой жизни и постоянного воздержания от употребления ПАВ [2].

C середины XX века в мире широкое распространение получила продолжительная реабилитация наркозависимых в стационарных условиях, где осуществляется программа 12 шагов, разработанная сообществом Анонимные Наркоманы. Это сообщество появилось в 1953 году и охватывает на сегодняшний день 137 стран. В России оно существует с 1990 года, теперь уже в 200 городах. 
Это закрытые центры для зависимых от ПАВ с длительным многомесячным пребыванием, от 6 месяцев до 1-ого года, которые, как правило, находятся в сельской местности рядом с крупными городами. При них же возникают терапевтические сообщества, где наркоманы получают индивидуальную и групповую психотерапевтическую помощь, различные фрормы трудотерапии и духовного наставничества. Сотрудники центра могут быть бывшие зависимые, которые прошли полный курс выздоровления, а также профессиональные психологи, педагоги и социальные работники [3].

Серьезным препятствием для повышения эффективности выздоровления больных наркоманией является негативное отношение СМИ к системе реабилитационных центров, а также до конца не решен вопрос об использовании в наркологических учреждениях помощи специально подготовленных психологов, знающих проблему аддикции и зависимости от ПАВ. Ежегодно в России тысячи зависимых от ПАВ проходят социально-психологическую реабилитацию и остаются В долгой ремиссии. В то время как наркологи говорят об эффрективности медикаментозной помощи только от 3-х до 5\% наркозависимым.

Среди реабилитационных центров, находящихся недалеко от Москвы, самым лучшим признан Молодежный Центр Здоровой Жизни, который уже работает более 5-ти лет. Ежегодно через данный центр проходят сотни наркозависимых, которым оказывается квалифицированная психологическая помощь. Число обратившихся наркоманов постоянно растет. Так, за последние годы помощь получили 723 наркозависимых. В 2017 году 160 человек, из них мужчин 69\% в возрасте от 18-ти до 49-ти лет, и женщин - 31 \% в возрасте от 18-ти до 45-ти лет. В 2018 году - 406, из них наркоманов-мужчин 72 \% в возрасте от 18 до 47 лет, и женщин - 28 \% в возрасте от 18 до 45 лет.

В настоящее время медицинское лечение и социально-психологическая реабилитация оказывают помощь зависимым от ПАВ совместно, как единая программа, направленная на одну цель - выздоровление наркомана.

\section{Литература}

1. Менделевич В. Д. Недобровольное (принудительное) и альтернативное лечение наркомании: дискуссионные вопросы теории и практики // Наркология - 2007 -№7 - с.66-75

2. Когнитивно-поведенческая терапия расстройств, вызванных употреблением психоактивных веществ // Новости медицины и фармации - 2011 - №383

3. Плоткин Ф. Б. Новые тенденции в российской наркологии: возврат к старым силовым методам принудительного лечения // независимый психиатрический журнал - 2015 - №4 - С. 13-24

4. Koob G. F., Moal M. L. Neurobiology of Addiction. - Oxford.: Academic Press, 2006.- C. -503 
5. Russian.rf.com.news

6. www.unodc.org

\section{SOME ASPECTS OF PSYCHOLOGICAL CARE FOR PERSONS DEPENDING ON PSYCHOACTIVE SUBSTANCES (SAS)}

Avanesyan G.G. (Moscow Aviation Institute - National Research University, Moscow, Russia)

This article discusses the problem of dependence on psychoactive substances, the growth of drug addiction in the world, methods of providing medical and psychological assistance. It describes the forms of physical and psychological dependence on psychoactive substances, the international program for the rehabilitation of drug addicts according to the program of 12 steps, which has been successfully implemented in recent years in Russia too, which allows drug addicts to be in prolonged remission.

Key words: addiction, addictive behavior, drug addiction, rehabilitation. 